\title{
Características morfoagronômicas do milho submetido a diferentes níveis de desfolha manual
}

\author{
Marcel José Roma Pereira ${ }^{1}$, Everton César Biazotti Bonan ${ }^{1}$, Anice Garcia ${ }^{2}$, Ricardo de Lima Vasconcelos ${ }^{3 *}$, \\ Karina dos Santos Gíacomo ${ }^{4}$, Marcelo Ferreira Limal
}

\begin{abstract}
RESUMO
O presente trabalho foi realizado com o objetivo de avaliar os danos causados pela desfolha na cultura do milho. O experimento foi desenvolvido no ano agrícola 2005/2006, na Fazenda Roma, localizada no município de Ituverava, Estado de São Paulo. Para a sua concretização utilizou-se o híbrido triplo CODETEC 304®. O experimento foi composto de parcelas subdivididas, que foram distribuídas em três blocos de forma casualizada, apresentando como tratamento principal a desfolha manual (30, 40, 60 e 80\% de desfolha) e como secundário as fases fenológicas da cultura D1 (sete folhas completamente desenvolvidas), D2 (quando as plantas apresentam-se na fase de pendoamento) e D3 (quando as plantas apresentam-se na fase de enchimento de grãos-grãos leitosos) com três repetições para cada tratamento e uma parcela controle ( $0 \%$ de desfolha) para cada bloco. Foram avaliados a produção de grãos das parcelas $\left(\mathrm{g} / \mathrm{m}^{2}\right), \mathrm{o}$ tamanho médio das espigas despalhadas $(\mathrm{cm})$ e o peso médio de 1.000 grãos $(\mathrm{g})$. Para o presente estudo, concluiu-se que as relações fonte-dreno foram afetadas negativamente em que a desfolha de $80 \%$ foi a que mais afetou todas variáveis, portanto é um nível de desfolha responsável pelas maiores perdas, não havendo meios de compensação para a cultura do milho.
\end{abstract}

Palavras-chave: Zea mays, espiga, produtividade de grãos.

\section{ABSTRACT}

\section{Morphoagronomic characteristics of maize in response to different levels of defoliation}

The present study was conducted to evaluate the damage caused by defoliation in maize. The experiment was carried out in 2005/2006 at Roma Farm, Ituverava-SP, using the triple hybrid CODETEC 304®. The experiment consisted of split plots (split-plot), which were distributed at random in three blocks, with the main treatment manual defoliation (30\%, 40\%, 60\% and 80\% defoliation) in the plots and as the secondary treatment the phenological phases (D1, D2 and D3) with three replicates for each treatment and a control plot ( $\% \%$ defoliation) for each block. It was evaluated the production of plots $\left(\mathrm{g} / \mathrm{m}^{2}\right)$, the average size of the spikes $(\mathrm{cm})$ and the average weight of thousand grains $(\mathrm{g})$. According to the results, it was concluded that the source-sink relations were negatively affected, and the treatment with $80 \%$ defoliation was the one that most affected all variables, thus, it is a level of defoliation that is responsible for the largest losses, with no means of compensation for the maize crop.

Key words: Zea mays L., cob, grain yield.

Recebido para publicação em 25/10/2010 e aprovado em 06/03/2012

${ }^{1}$ Engenheiros-Agrônomos. Faculdade Dr. Francisco Maeda/FAFRAM, Rodovia Jerônimo Nunes Macedo, Km 01, 14500-000 Ituverava, São Paulo, Brasil. marcelroma@ig.com.br; evertonremo@hotmail.com; marcelolima.cta@hotmail.com.

${ }^{2}$ Engenheira-Agrônoma, Doutora. Faculdade Dr. Francisco Maeda/FAFRAM, Rodovia Jerônimo Nunes Macedo, Km 01, 14500-000 Ituverava, São Paulo, Brasil. anice@feituverava.com.br.

${ }^{3}$ Engenheiro-Agrônomo. Mestrando em Agronomia: Ciência do Solo, Universidade Estadual Paulista "Júlio de Mesquita Filho" (UNESP), Campus de Jaboticabal, Via de acesso Prof. Paulo Donato Castellane s/n, 14884-900 Jaboticabal, São Paulo, Brasil. ricardo-matao-sp@hotmail.com. (*autor para correspondência).

${ }^{4}$ Engenheira-Agrônoma. Centro de Engenharia e Automação do Instituto Agronômico de Campinas (CEA/IAC), Rodovia Dom Gabriel Paulino Bueno Couto, Km 65, CP 26, 13201970 Jundiaí, São Paulo, Brasil. karinagiacomo@ hotmail.com. 


\section{INTRODUÇÃO}

O milho (Zea mays L.) é importante planta comercial originária das Américas, economicamente é representado pelas diferentes formas de sua utilização, que se inicia na alimentação animal e se estende na indústria de alta tecnologia, fazendo com que ele seja uma das mais importantes commodities do setor agrícola no Brasil.

O estresse é definido como fator externo, que exerce influência desvantajosa para o crescimento e desenvolvimento da planta, reduzindo significativamente o desempenho vegetal (DaMatta \& Ramalho, 2006). Na maioria dos casos, o estresse é medido em relação à sobrevivência, produtividade agrícola, acumulação de biomassa ou ao processo primário de assimilação, relacionados ao crescimento e desenvolvimento da planta (Gondim, 2006).

Os estresses por desfolhamento alteram a relação fonte-dreno das plantas, com reflexos na redução da produtividade do vegetal, consequentemente afetando o rendimento econômico (Daros et al., 2000). Injúrias foliares podem levar à alteração na relação fonte-dreno das plantas, e essa alteração pode provocar mudanças nas características agronômicas que afetam a produção e a qualidade fisiológica das sementes. A fotossíntese, a formação e remobilização de reservas e o estabelecimento de grãos viáveis são ocorridos durante o estresse; acarretando, consequentemente, variações no comportamento das relações fonte-dreno (Gondim, 2006). O desenvolvimento dos grãos é resultado pelo balanço entre a capacidade da planta suprir fotoassimilados (fonte) para os grãos e do seu próprio potencial de utilização de substratos disponíveis (Gondim, 2006).

A perda da área foliar, causada por doenças, insetos, geadas, granizo, vento e déficit hídrico, interfere diretamente na produtividade biológica do milho, por alterar suas características fisiológicas. Os efeitos que os estresses provocam na cultura do milho têm sido estudados com a finalidade de entender as alterações morfológicas que ocorrem nas plantas que, em geral, são responsáveis pela perda de rendimento.

Essa característica, aliada à pequena plasticidade foliar, reduzida prolificidade e limitada capacidade efetiva de compensação de espaços, faz com que o seu cultivo necessite ser rigorosamente planejado e criteriosamente manejado, para que possa manifestar sua capacidade produtiva (Andrade, 1995; Sangoi et al., 2007).

A produção de milho é resultante do produto entre número de espigas, número de grãos em cada espiga e peso médio dos grãos. Na maioria dos casos, entretanto, a produção está mais associada ao número de grãos do que com seu peso médio, ou com o número de espigas por planta (Otegui \& Andrade, 2000).
As alterações fenológicas que ocorrem dentro da planta podem ter influência sobre as características morfofisiológicas da cultura (Mundstock, 1999).

Quando a desfolha ocorre próximo à época de florescimento, ela promove significativa queda na produtividade da cultura, principalmente pela redução do comprimento de espigas, peso de espigas e peso de grãos (Fancelli, 1988). O período crítico no ciclo vital do milho inicia-se, aproximadamente, duas semanas antes da antese e se prolonga por duas a três semanas após. A ocorrência de estresse antes do florescimento pode causar retração no desenvolvimento da espiga, enquanto anormalidades durante e após a polinização poderão resultar no abortamento e na redução do número e peso de grãos (Daynard \& Duncan, 1969). A remoção de folha, após a polinização diminuiu a massa de grãos e o período para o seu enchimento (Britz, 1982).

A participação de folhas na produção e a distribuição da matéria seca em milho após o florescimento também foram avaliadas por Allison \& Watson (1966). A análise dos resultados evidenciou que a maior parte do acúmulo de matéria seca após o florescimento foi proporcionado pelas folhas superiores.

A desfolha pode também afetar a formação do grão, visto que a retirada das folhas acima da espiga aos 12 e 24 dias após $50 \%$ da emissão do estilo-estigmas, segundo Jones \& Simmons (1983), promoveu a redução do desenvolvimento do grão e a duração do período de enchimento, principalmente na primeira época de desfolha.

Quando a desfolha consistiu na remoção de folhas superiores de plantas em floração, a maioria dos resultados apresentados evidenciou significativa queda de produção, demonstrando a importância das folhas do ápice da planta no rendimento final. Dos componentes da produção mais afetados pela desfolha nesse período, destaca-se o número, tamanho e o peso de espigas, além do número e peso de grãos.

Fancelli (1988), em experimento de campo, submeteu plantas de milho à desfolha das cinco folhas superiores, em cinco épocas diferentes, e concluiu que quando a desfolha acontece próximo à época do florescimento ocorre significativa queda na produtividade biológica da cultura, principalmente pela redução do comprimento de espigas, peso de espigas e peso de grãos. O objetivo deste trabalho foi avaliar as características morfoagronômicas do milho sob efeito de diferentes níveis de desfolha em três fases fenológicas.

\section{MATERIAL E MÉTODOS}

O experimento foi conduzido no ano agrícola 2005/ 2006, na área comercial da Fazenda Roma, localizada às margens da Rodovia Alfredo Pimenta, no município de

Rev. Ceres, Viçosa, v. 59, n.2, p. 200-205, mar/abr, 2012 
Ituverava, Estado de São Paulo (20 22' 21.1' ' S, 47 45' 19.4" W e altitude de $623 \mathrm{~m}$ ), com clima tipo Aw, tropical com verão chuvoso e inverno seco (Carrer \& Garcia, 2007), relevo levemente ondulado, sendo o solo predominante um latossolo Vermelho Acriférrico.

O híbrido utilizado foi o COODETEC $304^{\circledR}$, um triplo de ciclo superprecoce, com população de plantas por hectare da ordem de 50.000 a 55.000, com floração de 68 a 72 dias após a germinação, sendo a altura da planta de 1,85 a $1,93 \mathrm{~m}$ e a da inserção da espiga de 1,00 a $1,10 \mathrm{~m}$ em relação ao solo (Coodetec, 2006). A espiga apresenta grão duro e alaranjado, com moderada resistência a Phaeospheris maydis e helmintosporiose, sendo também moderadamente susceptível à ferrugem comum e moderadamente resistente às podridões de colmo. $\mathrm{O}$ plantio mecânico foi realizado no dia 28/11/2005, de acordo com as recomendações de Fahl et al. (1998). As adubações foram baseadas na metodologia de van Raij et al. (1997).

As sementes foram tratadas com o inseticida carbamato, e foram feitas três aplicações para o controle das lagartas elasmo (Elasmopalpus lignosellus) e do cartucho (Spodoptera frugiperda), sendo a primeira realizada 10 dias após o plantio com piretróide, a segunda aos 37 dias após o plantio com acilureia e piretróide e a última com acilureia. Para as adubações aplicaram-se $50 \mathrm{~kg} \mathrm{ha}^{-1}$ de $\mathrm{N}$ (sulfato de amônio), $50 \mathrm{~kg} \mathrm{ha}^{-1} \mathrm{de}_{2} \mathrm{O}_{5}$ (superfosfato simples) e $50 \mathrm{~kg} \mathrm{ha}^{-1}$ de $\mathrm{K}_{2} \mathrm{O}$ (cloreto de potássio). Para as aplicações de cobertura utilizaram-se $140 \mathrm{~kg} \mathrm{ha}^{-1} \mathrm{de} \mathrm{N}$ (sulfato de amônio), em duas vezes, uma quando as plantas apresentavam quatro pares de folhas (25/12/2005) e outra quando elas estavam com seis pares (25/01/2006). As plantas possuíam quatro e seis folhas completamente desenvolvidas, respectivamente. O controle de plantas daninhas foi realizado aos 23 dias após o plantio, mecanicamente, com uso de um cultivador de enxadas, em área total, e capina manual foi realizada somente na área de cada parcela, quando se julgava necessário.

O experimento foi composto de parcelas subdivididas (Split-Plot), que foram distribuídas em três blocos de forma casualizada, apresentando como tratamento principal a desfolha (mediu-se o comprimento de cada folha, quando se calculou a porcentagem a ser cortada. A desfolha foi feita manualmente, retirando-se parte do limbo foliar de acordo com cada tratamento: 30, 40, 60 e $80 \%$ de desfolha) e como tratamento secundário as fases fenológicas da cultura (D1 - quando as plantas apresentam sete folhas completamente desenvolvidas, D2 - quando elas encontram-se na fase de pendoamento e D3 - quando as plantas apresentam-se na fase de enchimento de grãos-grãos leitosos), com três repetições para cada tratamento e uma parcela controle ( $0 \%$ de desfolha) para cada bloco, segundo metodologia adaptada de Hsu (1978) e Vasilas \& Seif (1985). Foram avaliadas a variável produ- tividade biológica por parcela experimental (quilogramas de grãos $/ \mathrm{m}^{2}$ ), o tamanho médio das espigas por parcela $(\mathrm{cm})$ e peso de 1.000 grãos por parcela (gramas). Cada parcela possui $4,5 \mathrm{~m}^{2}$ (cinco linhas de plantio, e cada linha apresentava cinco metros de comprimento e espaçamento entrelinhas de 0,9 metros), totalizando $22,5 \mathrm{~m}^{2}$.

A primeira desfolha foi realizada quando as plantas tinham sete folhas totalmente expandidas (13/01/2006), a segunda no momento da emissão do estilete estigma (09/ 02/2006) e a terceira foi realizada durante a fase de enchimento dos grãos-grãos leitosos (14/02/2006). A umidade dos grãos foi determinada pelo método da estufa (Brasil, 2009), e a colheita foi realizada manualmente em 19/04/ 2006. A umidade encontrada nos grãos foi de $14 \%$.

Os dados foram submetidos ao teste F pela análise de variância, e as médias comparadas pelo teste de Tukey a 5\%, segundo Banzatto \& Kronka (2006).

\section{RESULTADOS E DISCUSSÃO}

O número de grãos por planta é influenciado por fatores genéticos e ambientes, principalmente nos estádios fenológicos de florescimento (III), frutificação (IV) e maturação $(\mathrm{V})$, pois nessas fases há definição do potencial de produção de grãos, e qualquer desequilíbrio afetará a produtividade biológica da planta. $\mathrm{O}$ tamanho da espiga e o número de espigas por planta afetam o número de grãos por planta. $\mathrm{O}$ rendimento da cultura depende da população empregada, estando essa relacionada ao sistema de produção, do índice e da duração da área foliar fotossinteticamente ativa, do número e da densidade grãos por espiga, do número de espiga por planta, entre outros (Vieira Junior \& Dourado Neto, 2008).

De acordo com a Tabela 1, foi possível observar que quando a desfolha foi realizada no estádio de sete folhas totalmente expandidas, a produtividade biológica das plantas não foi afetada. Portanto, nesse estádio de desenvolvimento há elevada capacidade da cultura em relação à recuperação dos aparelhos fotossintéticos e de eficiência que eles possuem em converter luz em fotoassimilados.

$\mathrm{Na}$ fase de pendoamento (D2) houve redução da produtividade biológica de milho em aproximadamente $24 \mathrm{e}$ $49 \%$ quando a cultura foi submetida à desfolha de $60 \mathrm{e}$ $80 \%$, respectivamente. Esse fato ressalta a importância do desenvolvimento foliar dessa fase, principalmente para o posterior desenvolvimento reprodutivo.

Durante a fase de enchimento de grãos leitosos (D3) apenas a desfolha drástica de $80 \%$ reduziu a produção de grãos em $51 \%$.

Corroborando com essa ideia, Sangoi et al. (2001) comentaram que materiais precoces e superprecoces dispõem de menos tempo para se recuperar de restrições ambientais impostas ao aparato fotossintético da planta nas fases de pré-floração, floração e início de enchimento de grãos. 
Na Tabela 2 observa-se que a variável produtividade de grãos em $\mathrm{g} / \mathrm{m}^{2}$ foi mais afetada pelo fator desfolha, apesar de também ter sido influenciada pelo fator fases, o que reforça a importância direta da integridade física do aparelho fotossintético na transferência de fotoassimilados para os grãos. Para a variável peso de 1.000 grãos, as plantas de milho foram afetadas pela interação desfolha e fases e por esses fatores individualmente. Observa-se que a fase foi a que mais influenciou nessa variável, visto que nas fases grãos leitosos e enchimento de grãos ocorrem consolidação da massa de grãos a ser produzida e que interferências nessa fase reduzem o aporte de fotoassimilados para os grãos que, consequentemente, serão mais leves. O tamanho da espiga foi influenciado por todas as fontes de variação, e o fator desfolha foi o responsável pela maior influência na planta, corroborando com a direta relação aparelho foliar e produção/desenvolvimento da espiga.

Tabela 1. Separação de médias para produtividade de grãos em g/ $\mathrm{m}^{2}(\mathrm{~g})$, tamanho de espiga $(\mathrm{cm})$ e peso de 1.000 grãos $(\mathrm{g})$ para o milho COODETEC $304^{\circledR}$

\begin{tabular}{|c|c|c|c|}
\hline $\begin{array}{l}\text { Fontes de } \\
\text { variação }\end{array}$ & $\begin{array}{l}\text { Produtividade } \\
\text { de grãos }\end{array}$ & $\begin{array}{l}\text { Tamanho } \\
\text { de espiga }\end{array}$ & $\begin{array}{c}\text { Peso } \\
1.000 \text { grãos }\end{array}$ \\
\hline \multicolumn{4}{|l|}{ Desfolha } \\
\hline $0 \% \quad(\mathrm{~A})$ & $364,29 \mathrm{~A}$ & $16,00 \mathrm{~A}$ & $303,33 \mathrm{~A}$ \\
\hline $30 \%$ (B) & $355,35 \mathrm{~A}$ & $15,72 \mathrm{~A}$ & $295,55 \mathrm{~A}$ \\
\hline $40 \%(\mathrm{C})$ & $347,33 \mathrm{~A}$ & $15,52 \mathrm{~A}$ & $293,11 \mathrm{~A}$ \\
\hline $60 \%$ (D) & $301,40 \mathrm{~A}$ & $15,47 \mathrm{~A}$ & $281,22 \mathrm{~A}$ \\
\hline $80 \%(\mathrm{E})$ & $234,22 \mathrm{~A}$ & $14,32 \mathrm{~A}$ & $245,22 B$ \\
\hline \multicolumn{4}{|l|}{$\overline{\text { Fases }}$} \\
\hline D1 & $352,98 \mathrm{~A}$ & $15,74 \mathrm{~A}$ & $297,66 \mathrm{~A}$ \\
\hline D2 & $304,25 \mathrm{~B}$ & $15,60 \mathrm{~A}$ & $279,46 \mathrm{~B}$ \\
\hline D3 & $304,34 \mathrm{~B}$ & $14,88 \mathrm{~A}$ & $273,86 \mathrm{~B}$ \\
\hline Ax D1 & $364,29 \mathrm{Aa}$ & $16,00 \mathrm{Aa}$ & $303,33 \mathrm{~A}$ \\
\hline A x D2 & $364,29 \mathrm{Aa}$ & $16,00 \mathrm{Aa}$ & $303,33 \mathrm{~A}$ \\
\hline A x D3 & $364,29 \mathrm{Aa}$ & $16,00 \mathrm{Aa}$ & $303,33 \mathrm{~A}$ \\
\hline B x D1 & $360,83 \mathrm{Aa}$ & $15,76 \mathrm{Aa}$ & $295,66 \mathrm{~A}$ \\
\hline B x D2 & $350,27 \mathrm{Aa}$ & $15,50 \mathrm{Aa}$ & $299,33 \mathrm{~A}$ \\
\hline B x D3 & $354,92 \mathrm{Aa}$ & $15,90 \mathrm{Aa}$ & $291,66 \mathrm{Ab}$ \\
\hline C x D1 & $359,15 \mathrm{Aa}$ & $15,76 \mathrm{Aa}$ & $300,00 \mathrm{~A}$ \\
\hline $\mathrm{C} \times \mathrm{D} 2$ & $342,30 \mathrm{Aa}$ & $14,93 \mathrm{Aa}$ & $290,66 \mathrm{~A}$ \\
\hline $\mathrm{C} \times \mathrm{D} 3$ & $340,56 \mathrm{Aa}$ & $15,86 \mathrm{Aa}$ & $288,66 \mathrm{Ab}$ \\
\hline D x D1 & $343,65 \mathrm{Aa}$ & $15,60 \mathrm{Aa}$ & $300,33 \mathrm{~A}$ \\
\hline D x D2 & $278,56 \mathrm{Aab}$ & $15,00 \mathrm{Aa}$ & $276,33 \mathrm{~A}$ \\
\hline D x D3 & $281,98 \mathrm{Aa}$ & $15,83 \mathrm{Aa}$ & $267,00 \mathrm{~B}$ \\
\hline E x D1 & $336,92 \mathrm{Aa}$ & $15,56 \mathrm{Aa}$ & $289,00 \mathrm{~A}$ \\
\hline Ex D2 & $185,80 \mathrm{Bb}$ & $13,00 \mathrm{Cb}$ & $227,66 \mathrm{~B}$ \\
\hline Ex D3 & $179,94 \mathrm{Bb}$ & $14,40 \mathrm{Bb}$ & $218,66 \mathrm{C}$ \\
\hline
\end{tabular}

Dados seguidos de mesma letra (maiúsculas nas linhas e minúsculas nas colunas), não diferem entre si pelo teste de Tukey a 5\%. Fases: D1 - quando as plantas apresentam sete folhas completamente desenvolvidas, D2 - quando elas encontram-se na fase de pendoamento, D3 - quando as plantas apresentam-se na fase de enchimento de grãos-grãos leitosos.
A planta de milho não apresenta saturação fotossintética nos níveis de radiação natural, e quanto maior a captação de luz solar maior o acúmulo de reservas. As duas únicas barreiras quanto à captação de luz são arquitetura das folhas e sombreamento ocasionado pela emissão do pendão (Vieira Junior \& Dourado Neto, 2008).

Nas Figuras 1 e 2 são apresentados, respectivamente a produtividade e o peso de 1.000 grãos sob efeito de diferentes níveis de desfolha. Ambas as variáveis são afetadas de modo semelhante pelo fator desfolha, com decréscimo em seu valor conforme a elevação da desfolha.

A massa final das sementes não é dependente apenas do envio de fotoassimilados, mas também do número e do volume de células no endosperma (Vieira Junior \& Dourado Neto, 2008). Para Magalhães \& Jones (1990), as condições ambientes são fundamentais para a relação número e volume de células no endosperma, sendo a temperatura e umidade do ar propícias e o suprimento de fotoassimilados adequado, o rendimento é limitado apenas pelo potencial genético.

As variáveis peso de 1.000 grãos e tamanho da espiga, respectivamente (Figuras 3 e 4), quando avaliadas sob o efeito da desfolha dentro de cada fase fenológica, apresentam respostas também semelhantes, a única diferença

Tabela 2. Desdobramentos da análise de variância de efeitos principais e interações

\begin{tabular}{lcc}
\hline \multicolumn{3}{c}{ Produtividade por parcela/m² $(\mathbf{g})$} \\
\hline Fontes de variação & $\mathbf{F}$ & $\mathbf{P}$ \\
\hline Blocos & $0,88^{\mathrm{NS}}$ & 0,4526 \\
Desfolha & $16,95^{* *}$ & 0,0006 \\
Fases & $7,07^{* *}$ & 0,0048 \\
Desfolha x fases & $2,44^{\mathrm{NS}}$ & 0,0508 \\
C.V. desfolha & $12,27 \%$ & \\
C.V. fases & $12,77 \%$ & \\
\hline
\end{tabular}

\begin{tabular}{lcc}
\hline \multicolumn{3}{c}{ Peso de 1.000 grãos $(\mathbf{g})$} \\
\hline Fontes de variação & F & P \\
\hline Blocos & $0,06^{\mathrm{NS}}$ & 0,9430 \\
Desfolha & $18,69^{* *}$ & 0,0001 \\
Fases & $27,81^{* *}$ & 0,0001 \\
Desfolha x fases & $9,32^{* *}$ & 0,0001 \\
C.V. desfolha & $5,61 \%$ & \\
C.V. fases & $3,22 \%$ & \\
\hline
\end{tabular}

\begin{tabular}{lcc}
\hline \multicolumn{3}{c}{ Tamanho da espiga $(\mathbf{c m})$} \\
\hline Fontes de variação & $\mathbf{F}$ & $\mathbf{P}$ \\
\hline Blocos & $6,35^{*}$ & 0,0223 \\
Desfolha & $23,26^{* *}$ & 0,0002 \\
Fases & $11,17^{* *}$ & 0,0006 \\
Desfolha x fases & $2,92^{*}$ & 0,0249 \\
C.V. desfolha & $2,58 \%$ & \\
C.V. fases & $3,44 \%$ & \\
\hline
\end{tabular}

$*, * * \mathrm{e}^{\mathrm{NS}}$, respectivamente, significativos a $5,1 \%$ e não significativo. 


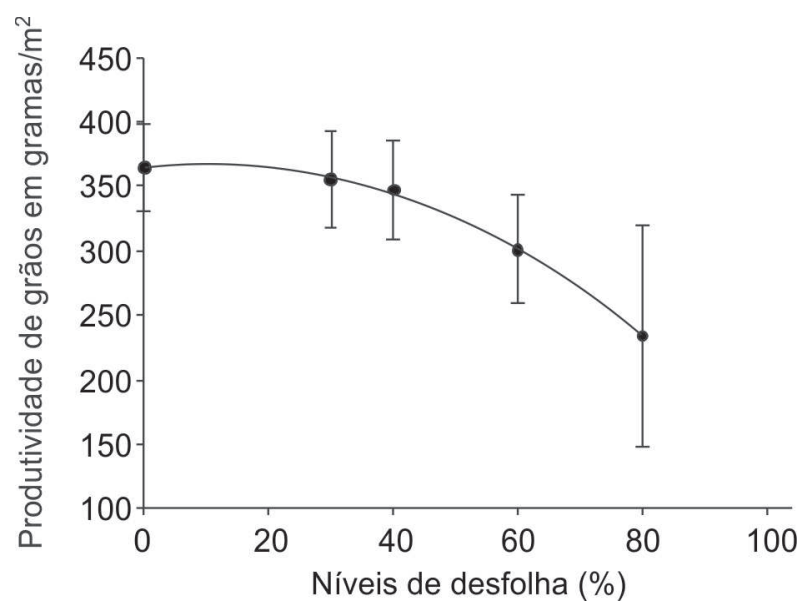

Figura 1. Produtividade de grãos em gramas $/ \mathrm{m}^{2}$ do milho sob efeito de diferentes níveis de desfolha. $\mathrm{Y}=8003,94240+$ $14,7060425 \mathrm{x}-0,62806959 \mathrm{x}^{2}, \mathrm{R}^{2}=0,99(\mathrm{p}<0,01)$.

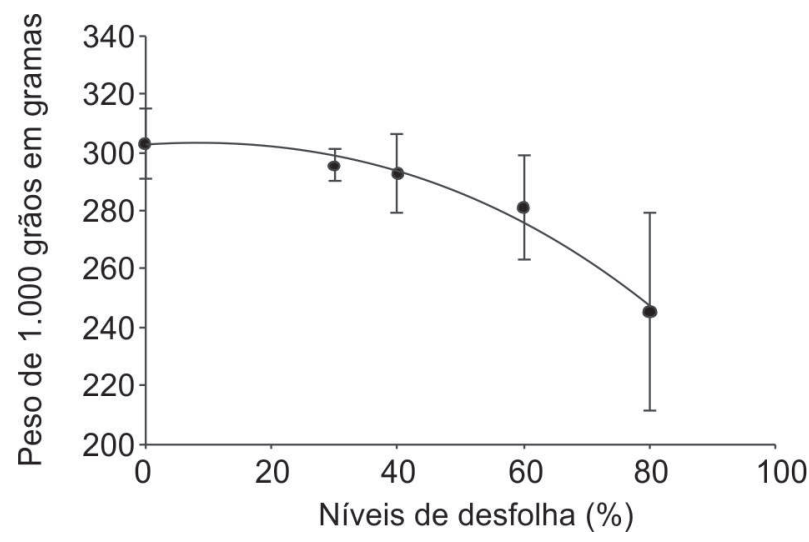

Figura 2. Peso de 1.000 grãos (g) de milho sob efeito de diferentes níveis de desfolha. $\mathrm{Y}=302,010317+0,26957861 \mathrm{x}-$ $0,01186638 x^{2}, R^{2}=0,97(p<0,01)$.

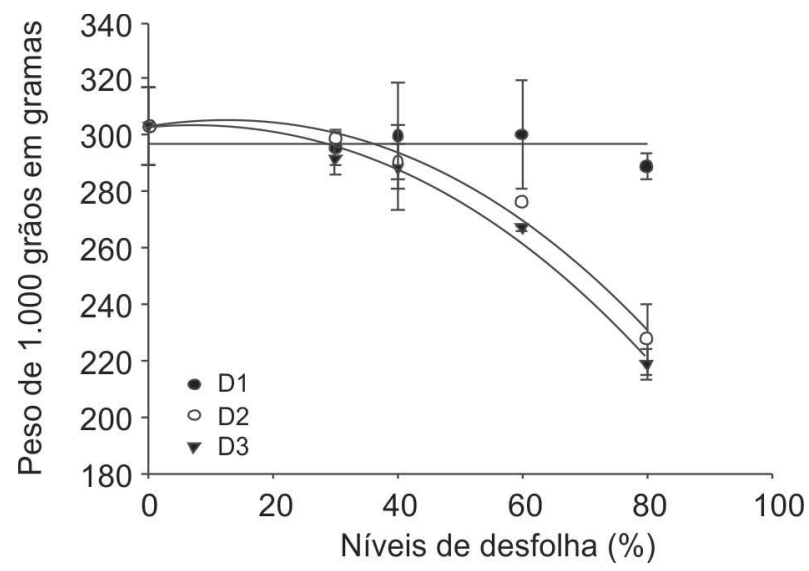

Figura 3. Peso de 1.000 grãos (g) de milho sob efeito da desfolha em cada fase fenológica (D1 - quando as plantas apresentam sete folhas completamente desenvolvidas, D2 - quando elas encontram-se na fase de pendoamento, D3 - quando as plantas apresentam-se na fase de enchimento de grãos-grãos leitosos). $D 1: Y=297,7^{\text {Ns }}$; $D 2: Y=302,137+0,4939 x-0,017366 x^{2}, R^{2}=$ $0,99(\mathrm{p}>0,01)$; $\mathrm{D} 3: \mathrm{Y}=301,857+0,3258 \mathrm{x}-0,01667 \mathrm{x}^{2}, \mathrm{R}^{2}=$ $0,99(\mathrm{p}>0,01)$.

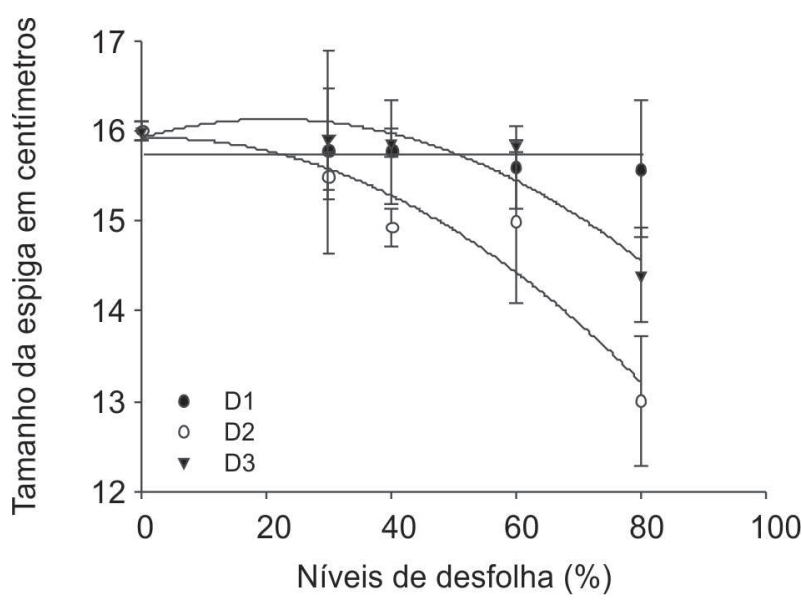

Figura 4. Tamanho da espiga de milho $(\mathrm{cm})$ sob efeito da desfolha em cada fase fenológica (D1 - quando as plantas apresentam sete folhas completamente desenvolvidas, D2 - quando elas encontram-se na fase de pendoamento, D3 - quando as plantas apresentam-se na fase de enchimento de grãos-grãos leitosos). D1: $\mathrm{Y}=15,7^{\mathrm{NS}}$; $\mathrm{D} 2: \mathrm{Y}=15,92+0,00216 \mathrm{x}-0,000448 \mathrm{x}^{2}, \mathrm{R}^{2}=$ $0,90(p>0,01)$; D3: $Y=15,92+0,01948 x-0,000456 x^{2}, R^{2}=$ $0,87(\mathrm{p}>0,01)$.

é que para peso de 1.000 grãos a desfolha de $80 \%$ na fase D3 (enchimento de grãos) foi mais prejudicada, possivelmente pela relação fonte-dreno ter sido deslocada para direita (dreno) pela insuficiência da planta em suprir os grãos. O tamanho da espiga foi mais afetado com a desfolha de $80 \%$ na fase D2 (pendoamento), demonstrando que essa fase é fundamental para a produção de espigas de tamanho padronizado.

\section{CONCLUSÕES}

De acordo com os resultados e com base nas condições edafoclimáticas da região, conclui-se que as relações fonte-dreno são afetadas negativamente e que a desfolha de $80 \%$ é a que mais afeta todas variáveis, portanto é o nível de desfolha o responsável pelas maiores perdas, não havendo meios de compensação pela cultura do milho.

\section{REFERÊNCIAS}

Allison JCS \& Watson DJ (1966) The production and distribution of dry matter in maize after flowering. Annals of Botany, 30:391-399.

Andrade FH (1995) Analysis of growth and yield of maize, sunflower and soybean grown at Balcarce, Argentina. Field Crops Research, 41:1-12.

Banzatto DA \& Kronka SN (2006) Experimentação agrícola. 4a ed. Jaboticabal, FUNEP. 237p.

Brasil (2009) Regras para análise de sementes. 1 $1^{a}$ ed. Brasília, Ministério da Agricultura, Pecuária e Abastecimento. 309p.

Britz GD (1982) The effect of defoliation at various growth stages on maize grain yield. Crop Production, 11:85-89.

Carrer TT \& Garcia A (2007) Classificação climática para a cidade de Ituverava/SP. Nucleus, 4:39-47. 
Coodetec (2006) Milho: Características do Cv. 304. CD-ROM.

DaMatta FM \& Ramalho JDC (2006) Impacts of drought and temperature stress on coffee physiology and production: a review. Brazilian Journal Plant Physiology, 18:55-81.

Daros E, Ronzelli Júnior P, Costa JA \& Koehler HS (2000) Estresses por sombreamento e desfolhamento no rendimento e seus componentes da variedade de feijão "carioca". Scientia Agrária, 1:55-61.

Daynard TB \& Duncan WG (1969) The black layer and grain maturity in corn. Crop Science, 9:831-834.

Fahl JI, Camargo MBP, Pizzinatto MA, Betti JA, Melo AMT, DeMaria IC \& Furlani AMC (1998) Instruções agrícolas para as principais culturas econômicas. $6^{\mathrm{a}}$ ed. rev. atual. Campinas, IAC. 393p. (Boletim 200)

Fancelli AL (1988) Influência do desfolhamento no desempenho de plantas e sementes de milho (Zea mays L.). Tese de Doutorado. Escola Superior de Agricultura "Luiz de Queiroz", Piracicaba. 172p

Gondim TCO (2006) Efeito de desfolha nas características agronômicas e na qualidade fisiológica de sementes de trigo. Tese de Doutorado. Universidade Federal de Viçosa, Viçosa. 71p.

Hsu FH (1978) Study on the effects of early defoliation on the agronomic traits of maize (Zea mays L.) under different plant population densities. Journal of the Taiwan Livestock Research, 11:63-71

Jones RJ \& Simmons SR (1983) Effect of altered source-sink ratio on growth of maize kernels. Crop Sciences, 1:129.
Magalhães PC \& Jones R (1990) Aumento de fotoassimilados na taxa de crescimento e peso final dos grãos de milho. Pesquisa Agropecuária Brasileira, 25:1747-1754.

Mundstock CM (1999) Bases fisiológicas para aumentar o rendimento de milho no sul do Brasil. In: $2^{\text {a }}$ Reunião Técnica Catarinense de Milho e Feijão, Lages. Resumos. p.31-33.

Otegui M \& Andrade FH (2000) New relationships between light interception, ear growth, and kernel set in maize. In: Westgate ME \& Boote KJ (Ed.) Physiology and modeling kernel set in maize. Madison, CSSA. p.89-102.

Sangoi L, Almeida ML, Lech VA, Gracietti LC \& Rampazzo C (2001) Desempenho de híbridos de milho com ciclos contrastantes em função da desfolha e da população de plantas. Piracicaba, Scientia Agrícola, 58:271-276.

Sangoi L, Silva PRF, Argenta G \& Rambo L (2007) Desenvolvimento e exigências climáticas da planta de milho para altos rendimentos. Lages, Graphel. 96p.

van Raij B, Cantarela H, Quaggio JA \& Furlani AMC (1997) Recomendações de adubação e calagem para o Estado de São Paulo. $2^{a}$ ed. rev. atual. Campinas, IAC. 285p. (Boletim 100)

Vasilas BL \& Seif RD (1985) Pre-anthesis defoliation effects on six corn inbreds. Agronomy Journal, 77:831-835.

Vieira Junior PA \& Dourado Neto D (2008) Milho. In: Castro PR de C, Kluge RA \& Sestari I (Eds.) Manual de fisiologia vegetal: fisiologia de cultivos. $1^{\text {a }}$ ed. Piracicaba, Ceres. p.130-156. 